Am. J. Nephrol. 1988;8:254

\title{
Medical Art
}

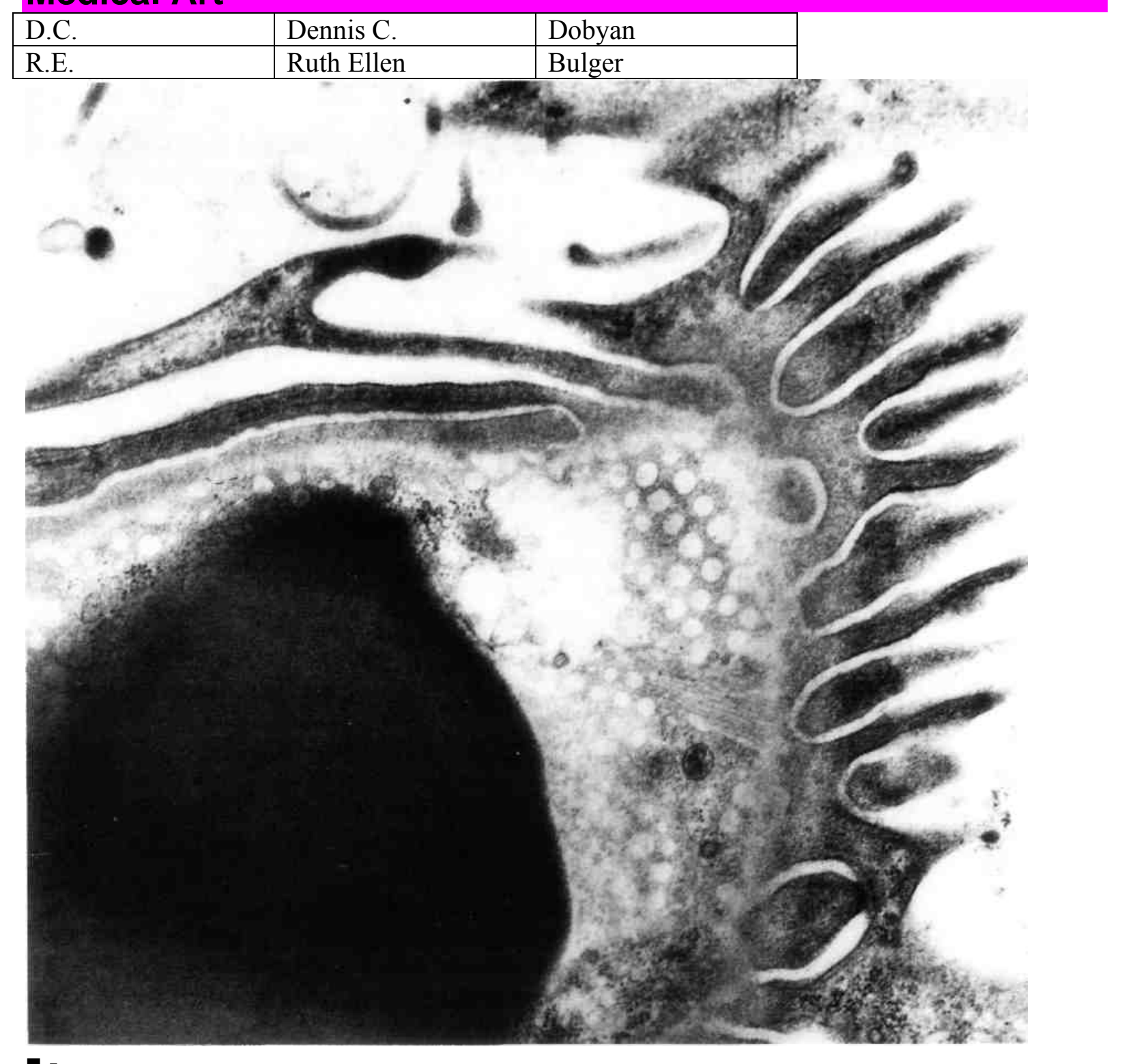

-

Pig's Kidney

Transmission electron micrograph of a pig kidney showing a grazing cut through the glomerular filtration barrier: the fenestrated endothelium, the basement membrane and the pedicels. Note the secondary process in the upper part of the figure terminating as a tertiary process or pedicel that 
interdigitates with an adjacent pedicel. The black sphere in the lower part of the figure is a red blood cell. X 38,000. 